\title{
MULTIETHNIC NEIGHBORHOODS ON THE GROUND
}

\section{Resources, Constraints, and Sense of Community}

\author{
Emily Walton \\ Department of Sociology, Dartmouth College \\ Mae Hardebeck \\ Department of Sociology, Dartmouth College
}

\begin{abstract}
As our nation and our neighborhoods increasingly diversify, we should understand how to sustain integrated communities that are equally beneficial for all residents. Though our policies encourage diversity as a theoretical social good, we actually know little about what happens on the ground in multiethnic neighborhoods. We conduct a comparative case study of the only two Boston neighborhoods to have maintained at least $10 \%$ representation of four racial and ethnic groups over the past two decades. Using survey data and ethnographic field observations, we examine residents' experiences in these two consistently multiethnic, yet very different, neighborhoods. We find that neighborhood socioeconomic and racial inequality and disadvantage matter for residents' access to neighborhood resources and constraints, and their perceptions of sense of community. Notably, in the highly unequal South End, Whites and homeowners have greater access to amenities and have higher perceptions of sense of community in comparison to racial and ethnic minorities and renters. Socioeconomic disadvantage matters in Fields Corner, as evidenced by lower overall perceptions of sense of community and greater exposure to safety concerns among all groups in this neighborhood compared to residents of the South End. In the end, we argue that having multiple groups simply sharing neighborhood space over a stable period is not enough to overcome the social problems associated with residential segregation and isolation. In order to support equitable neighborhood integration amid the changing face of diversity, we should take cues from "diverse by direction" neighborhood models that include active organization and coalition building among dissimilar racial and ethnic groups.
\end{abstract}

Keywords: Multiethnic Neighborhoods, Racial Inequality, Socioeconomic Inequality, Neighborhood Disadvantage, Sense of Community

To build community requires vigilant awareness of the work we must continually do to undermine all the socialization that leads us to behave in ways that perpetuate domination. 


\section{INTRODUCTION}

As we continue to incorporate immigrants and their children into U.S. society in relatively large numbers (Passel and Cohn, 2008), our neighborhoods are becoming increasingly diverse in ways we have never before experienced (Fong and Shibuya, 2005; Logan and Zhang, 2010; Timberlake and Iceland, 2007). Though some scholars have reflected on increasing neighborhood diversity with optimism (Glaeser and Vigdor, 2012), it is not entirely clear that our "integrated" neighborhoods overcome the social problems perpetuated by residential segregation (Mayorga-Gallo 2014). Part of the reason for this is that community building often entails processes of exclusion, or the active maintenance of boundaries and social distance from others (Cattell 2004). In fact, the conditions associated with long-lasting, tightly-knit communities are at odds with those supporting integration and respect for multiple groups (Neal and Neal, 2014; Townley et al., 2011), and scholars find that most multiethnic neighborhoods today are actually in the process of transition due to either White avoidance or gentrification (Crowder et al., 2012; Ellen 2000; Fasenfest et al., 2004; Friedman 2008; Lee and Hughes, 2014; Parisi et al., 2015). In addition, many neighborhoods that appear integrated from a bird's-eye-view of the data may actually be experiencing microsegregation on the ground, where residents of different groups are isolated in their everyday activities and participate in little meaningful interaction (Miller 2015; Tach 2014).

In many ways, we don't understand social dynamics and their implications in today's rapidly changing, multiethnic neighborhood environments. Our in-depth, comparative case study of two unusual neighborhoods - they have remained consistently multiethnic over the past two decades-builds on the largely descriptive neighborhood diversity literature with its in-depth analysis of residents' perceptions and experiences. We ask how differences in neighborhood inequality and disadvantage across these two neighborhoods are reflected in residents' appreciation of neighborhood resources, exposure to constraints, and perceptions of sense of community.

This study contributes to our understanding of Environmental Equity and Race in multiple ways. First, we draw on W. E. B. Du Bois's (1899) seminal study of the African American community in the Seventh Ward of Philadelphia in our conceptualization of neighborhoods as collections of physical, social, and cultural phenomena that are inextricably linked to individual quality of life and prospects for social mobility. While the word environment may call to mind the physical—such as the air we breathe or the water we drink-we recall how Du Bois encouraged students of inequality to, "notice the environment; the physical environment of city, sections and houses, [but also] the far mightier social environment - the surrounding world of custom, wish, whim, and thought which envelops [a] group and powerfully influences its social development" (Du Bois 2007 [1899], p. 3). Second, recognizing the importance of equity requires that scholarship critically evaluates the fairness of the processes that underlie observed differences across groups (Sen 2002). Our "on the ground" study of multiethnic neighborhoods goes beyond the existing literature's "bird's-eye view" of change to understand how structural factors may relate to the ways neighborhood diversity plays out in the daily lives and relationships among residents. Finally, we adopt an inclusive view of race in this study with our explicit focus on the ways immigration and natural population growth is altering the racial and ethnic landscape of the neighborhoods in which we live. We value and give voice to Asians, Latinos, African Americans, and Whites in our investigation of multiple perspectives and experiences in consistently multiethnic neighborhoods. 


\section{BACKGROUND}

\section{Why Do We Care about Neighborhood Integration?}

The United States has a long history of racial residential segregation (Logan and Stults, 2011), stemming from institutional-level policies aimed at keeping people of color out of certain neighborhoods (Massey and Denton, 1993; Pager and Shepherd, 2008) and individual-level preferences among Whites for living in racially homogeneous neighborhoods (Charles 2000; Krysan et al., 2009). The physical separation of minority groups in isolated neighborhoods is also often accompanied by economic and social marginalization (Adelman and Mele, 2015), such that resources and opportunities are more abundant in White neighborhoods and disadvantage is concentrated in predominantly minority neighborhoods (Briggs 2005; Squires and Kubrin, 2005). This entrenched residential exclusion not only poses challenges for those experiencing the isolation of urban poverty, but is considered the "linchpin" of persistent racial inequality (Massey 2016; Pettigrew 1979) because of its reciprocal effects on important institutions related to social mobility, such as education, the labor market, and the criminal justice system (Reskin 2012). Because of the cyclical nature and depth of social problems accompanying residential segregation, scholars and policy makers alike suggest that residential integration is imperative for a just, equitable society (Anderson 2010).

True integration is more than just proportional statistical representation of multiple groups in neighborhoods, but ideally involves residents taking action on behalf of community, or "genuine intergroup, interpersonal doing" (King 1986, p. 118). According to Gordon Allport's (1954) contact hypothesis, if specific conditions underlie acquaintanceship among dissimilar others, it may result in lower prejudice and transformation from the group-oriented concepts of "us" and "them" to the communityoriented concept of "we." Others argue that shared activity among unlike people may encourage new ways of thinking and mutual interdependence, so that the overall tenor of social interaction is more harmonious and cooperative in diverse communities (Anderson 2011; Jacobs 2011 [1961]). In part because of the purported benefits of diversity, federal housing policy has shifted toward new construction of mixed-income housing (Turner 1998), with the hopes that these neighborhoods will "bring people of diverse ages, races, and incomes into daily interaction - strengthening the personal and civic bonds essential to an authentic community" (The Congress for the New Urbanism 2000, p. 4). While, in principle, social justice and equity undergird society's encouragement of integration, we often find, in practice, that the realities of diverse communities do not live up to their designs (Fainstein 2005; Kleit 2005; Lewis et al., 2015).

Part of the reason rhetoric may not match reality is that our qualitative understanding of the experience and meaning of living in integrated neighborhoods is outdated. Much of the detailed evidence about social dynamics on the ground in integrated communities comes from a handful of studies regarding Black/White "diverse-by-direction" (Nyden et al., 1998) neighborhoods that resulted from the prointegration movement of the 1950s and 1960s (Keating 1994; Saltman 1990), where residents actively developed coalitions and organizations focused explicitly on supporting neighborhood integration. Today, integrated communities are increasingly likely to be "global neighborhoods" (Logan and Zhang, 2010, p. 1069), where native-born Whites and African Americans live side by side with foreign- and native-born Asian and Latino Americans (Fasenfest et al., 2004; Fong and Shibuya, 2005; Timberlake and Iceland, 2007). Unlike integrated communities of the past, today's multiethnic neighborhoods find their origins in recently liberalized immigration policies and 
economic globalization (Maly 2005). In our nation's new multiethnic "diverse-bycircumstance" (Nyden et al., 1998) neighborhoods, in which most residents "never intended to be neighbors" (Horton 1995, p. 33), we ask to what extent residents are able to benefit from decreasing segregation to participate in resourceful and socially cohesive communities?

\section{Multiethnic Neighborhoods and Social Relationships}

A growing quantitative literature proposes that increasing neighborhood diversity will adversely affect quality of life and social relationships (Frey 1996; Lichter 2013). One of sociology's most highly-regarded frameworks for understanding urban processes, the social disorganization perspective, considers racial heterogeneity to be one of the four key structural conditions threatening social cohesion in neighborhoods because it hampers communication and limits achievement of common goals (Kornhauser 1978; Sampson and Groves, 1989). Recent quantitative inquiries find that increasing neighborhood racial diversity is associated with lower participation in social activities (Alesina and La Ferrara, 2000), less trust and altruism (Putnam 2007), and perceptions of poor cooperation and social cohesion (Mennis et al., 2013).

Another set of scholars suggests that greater racial and ethnic diversity may not be harmful to social relationships, per se, but that the effects depend on contextual factors, namely neighborhood disadvantage and inequality (Portes and Vickstrom, 2011). Some research finds that the negative effect of diversity on social cohesion is just a small fraction of the effects of neighborhood economic disadvantage (Costa and Kahn, 2003; Laurence 2011; Letki 2008; Sturgis et al., 2010). Similarly, though Avery Guest et al. (2008) find that Whites are less likely to view neighbor relationships as "harmonious" in diverse neighborhoods, much of this relationship is explained by the relatively lower level of affluence in these areas. Socioeconomic and racial inequality also appear to influence social relationships in diverse neighborhoods. Maria Abascal and Delia Baldassarri (2015) find that the association between diversity and trust in communities is better explained by economic conditions, and that an analytic focus on "diversity" alone sidesteps issues of material and symbolic inequalities in communities. Lance Freeman's (2006) qualitative examination of inequality in gentrifying neighborhoods uncovers both positive and negative sentiments. On one hand, he finds native Black residents are receptive of the incoming middle-class White population because of the amenities they bring to the neighborhood; on the other hand, after decades of social isolation and exclusion, native residents are resentful that improvements are achieved only when White middle-class residents move in, and even then tend to serve the interests of the new gentry (Freeman 2006). Other qualitative investigations in unequal neighborhoods find that microsegregation of organizational and everyday activities inhibits meaningful integration among racially and socioeconomically diverse neighbors (Tach 2014; Tissot 2015).

\section{THE CURRENT STUDY}

As our nation and our neighborhoods adapt to the racial and ethnic changes of the twenty-first century, we, as citizens and scholars, should understand the building blocks of equitable multiethnic communities in which all residents may participate fully. Though most would agree that residential segregation is an entrenched and destructive social problem, there is still some uncertainty about whether neighborhood integration would support social cohesion and disrupt the cycle of disadvantage perpetuated in isolated neighborhoods. This uncertainty stems from an outdated 
qualitative understanding of the meaning of diversity, which does not consider the ways decades of relatively open immigration have changed the nature of multiethnic neighborhoods today. There is also lack of consensus among quantitative scholars about the effects of neighborhood diversity on social relationships, with some arguing that increasing diversity is harmful and others that the effects of diversity depend on contextual factors, such as inequality and disadvantage.

The current study contributes to this conversation in three ways. First, we take an in-depth look at the nature of community in multiethnic neighborhoods, which we define as having at least $10 \%$ representation of four different racial and ethnic groups. In doing so, we add to the literature on neighborhood diversity by considering the ways that individuals from multiple groups-Asian, Latino, White, and Black-experience multiethnic neighborhoods. Second, we investigate neighborhoods that are consistently multiethnic over a period of two decades. Given that most of today's multiethnic neighborhoods are in transition, we gain novel insight from an investigation of neighborhoods that maintain substantial representation of multiple groups over a longer period of time. Finally, we compare two very different multiethnic neighborhoods-one racially and socioeconomically unequal but relatively socioeconomically advantaged, and the other uniformly socioeconomically disadvantaged but relatively racially and socioeconomically equal. This comparison provides perspective on an ongoing scholarly debate regarding the effects of diversity in differing neighborhood contexts. Specifically, we consider two research questions:

1) How do residents belonging to different demographic groups—racial/ethnic and socioeconomic-perceive contextual resources/constraints and sense of community in multiethnic neighborhoods? (i.e., are there within-neighborhood differences in perceptions?)

2) How do residents living in different neighborhood types-one racially and socioeconomically unequal and the other socioeconomically disadvantaged-perceive structural resources/constraints and sense of community in multiethnic neighborhoods? (i.e., are there between-neighborhood differences in perceptions?)

\section{METHODS}

\section{The Settings}

We present a comparative case study of two Boston neighborhoods, the South End and Fields Corner. These neighborhoods are the only two consistently multiethnic census tracts in the city; that is, they maintain at least $10 \%$ representation of four major racial and ethnic groups over the twenty-year period from 1990-2010 (as shown in Table 1). Further, these neighborhoods present ideal conditions for a deeper exploration of theorized moderators of the relationship between diversity and social relationships-neighborhood disadvantage and racial/socioeconomic inequality.

The first neighborhood is a section of Boston's South End. In the early nineteenth century, the South End's location close to Boston's central business district made it attractive to upper class families (Green 1975); however, after the development of the nearby Back Bay, the South End lost its appeal and property values dropped. By the 1950 s, the South End was an economically poor, but culturally vibrant, community which had gained a negative reputation as a "skid row" (Tach 2014, p. 18), and consequently was subject to one of the largest urban renewal projects in the country. Activist residents effectively organized to preserve affordable housing during this process to ensure a mixed-income population well into the future (Kennedy 1992). Today, the 
Table 1. Selected Characteristics of Neighborhood Residents, 1990-2010

\begin{tabular}{|c|c|c|c|c|c|c|}
\hline \multirow[b]{2}{*}{ Characteristic } & \multicolumn{3}{|c|}{$\begin{array}{l}\text { South End } \\
\text { (Tract 712) }\end{array}$} & \multicolumn{3}{|c|}{$\begin{array}{l}\text { Fields Corner } \\
\text { (Tract 916) }\end{array}$} \\
\hline & 1990 & 2000 & 2010 & 1990 & 2000 & 2010 \\
\hline Total population size (\#) & 1485 & 1344 & 3131 & 2897 & 3448 & 3138 \\
\hline \multicolumn{7}{|l|}{ Racial and ethnic composition } \\
\hline Hispanic or Latino & $37 \%$ & $26 \%$ & $24 \%$ & $15 \%$ & $13 \%$ & $16 \%$ \\
\hline White & $19 \%$ & $36 \%$ & $47 \%$ & $41 \%$ & $17 \%$ & $16 \%$ \\
\hline Black or African American & $29 \%$ & $22 \%$ & $21 \%$ & $27 \%$ & $39 \%$ & $34 \%$ \\
\hline Asian/Pacific Islander & $15 \%$ & $15 \%$ & $15 \%$ & $10 \%$ & $18 \%$ & $26 \%$ \\
\hline Households (\#) & 464 & 471 & 1304 & 1031 & 1085 & 1043 \\
\hline Family & $41 \%$ & $38 \%$ & $45 \%$ & $58 \%$ & $68 \%$ & $68 \%$ \\
\hline Non-family & $59 \%$ & $62 \%$ & $55 \%$ & $42 \%$ & $32 \%$ & $33 \%$ \\
\hline Foreign born & $21 \%$ & $23 \%$ & $27 \%$ & $23 \%$ & $39 \%$ & $41 \%$ \\
\hline \multicolumn{7}{|l|}{ Language at home (5 years + ) } \\
\hline English & $50 \%$ & $57 \%$ & $57 \%$ & $65 \%$ & $50 \%$ & $46 \%$ \\
\hline Language other than English & $50 \%$ & $43 \%$ & $43 \%$ & $35 \%$ & $50 \%$ & $55 \%$ \\
\hline \multicolumn{7}{|l|}{ Education $(25$ years + ) } \\
\hline Less than 12 th grade & $26 \%$ & $41 \%$ & $22 \%$ & $19 \%$ & $41 \%$ & $35 \%$ \\
\hline High school graduate & $15 \%$ & $27 \%$ & $23 \%$ & $14 \%$ & $31 \%$ & $29 \%$ \\
\hline Some college, or Associate & $12 \%$ & $18 \%$ & $19 \%$ & $13 \%$ & $17 \%$ & $20 \%$ \\
\hline Bachelor's degree & $8 \%$ & $7 \%$ & $22 \%$ & $6 \%$ & $7 \%$ & $12 \%$ \\
\hline Graduate or professional & $7 \%$ & $8 \%$ & $14 \%$ & $4 \%$ & $4 \%$ & $5 \%$ \\
\hline Income below poverty (18 to 64 years) & $56 \%$ & $41 \%$ & $41 \%$ & $14 \%$ & $23 \%$ & $26 \%$ \\
\hline \multicolumn{7}{|l|}{ Household income } \\
\hline Less than $\$ 10,000$ & $59 \%$ & $24 \%$ & $22 \%$ & $28 \%$ & $14 \%$ & $18 \%$ \\
\hline$\$ 10,000-49,999$ & $35 \%$ & $51 \%$ & $38 \%$ & $55 \%$ & $54 \%$ & $45 \%$ \\
\hline$\$ 50,000-99,999$ & $6 \%$ & $11 \%$ & $16 \%$ & $16 \%$ & $28 \%$ & $29 \%$ \\
\hline$\$ 100,000-149,999$ & $0 \%$ & $8 \%$ & $6 \%$ & $0.5 \%$ & $4 \%$ & $5 \%$ \\
\hline$\$ 150,000$ or more & $0 \%$ & $7 \%$ & $18 \%$ & $0.7 \%$ & $0 \%$ & $2 \%$ \\
\hline Housing units (\#) & 780 & 471 & 1304 & 1145 & 1085 & 1043 \\
\hline Owner-occupied units & $1 \%$ & $21 \%$ & $37 \%$ & $23 \%$ & $24 \%$ & $27 \%$ \\
\hline Renter-occupied units & $69 \%$ & $79 \%$ & $63 \%$ & $69 \%$ & $76 \%$ & $73 \%$ \\
\hline
\end{tabular}

area is rapidly gentrifying, while many residents still laud the neighborhood's reputation for diversity (Tissot 2015).

The diversity in the South End occurs within the context of substantial racial and socioeconomic inequality. One can see gentrification happening over the twenty-year period, as the White population rose from $19 \%$ to $47 \%$ and those with incomes of $\$ 150,000$ or more rose from $0 \%$ to $18 \%$ of the population (see Table 1 ). While the neighborhood increased its shares of the White and wealthy population over time, it also maintained very large proportions of the population living below the poverty line $(41 \%)$, with low household incomes $(60 \%$ have a household income lower than $\$ 49,999$ per year), and with low educational attainment (22\% have not graduated from high school). Racially and ethnically, Black and Asian populations have remained fairly 
steady at approximately $25 \%$ and $15 \%$ respectively over the twenty-year period, however the largely Puerto Rican Latino population declined over time from 37\% in 1990 to $24 \%$ in 2010 .

The second neighborhood we study is a section in the central area of Dorchester called Fields Corner. In the early 1960s, a middle-class, mostly Irish, population characterized Fields Corner; however, White flight in the 1970s meant that neighborhood conditions deteriorated substantially for the remaining non-White residents. Beginning in the 1980s, Vietnamese immigrant business entrepreneurs economically revitalized the area (Watanabe 2009) and today it has become somewhat of an immigrant enclave, home to large proportions of Black (Caribbean Black, African American, and Cape Verdean), Asian (predominantly Vietnamese), Latino, and White groups.

In comparison to the South End, Fields Corner is less economically bifurcated and the multiethnic character does not appear to stem from gentrification processes; however, it is more socioeconomically disadvantaged. A majority of residents are lower to middle class, with the median income of most households remaining between $\$ 10,000$ and $\$ 49,999$ over the twenty-year period (see Table 1). Also contributing to the overall social disadvantage are low educational attainment-only $17 \%$ of residents twenty-five years or older have a college degree or higher, compared to $28 \%$ nationally in 2009 (Ryan and Siebens, 2012) — and the fact that a majority of the neighborhood population speaks a language other than English at home (55\%). The White population has declined over time from $41 \%$ in 1990 to $16 \%$ in 2010, while the population size and owner-occupied units remained relatively stable. Over the same time period, the Asian population increased from $10 \%$ to $26 \%$, while the Black and Latino populations remained stable at around $30 \%$ and $15 \%$ respectively.

\section{Data and Measures}

Analysis for the current study largely rests on questions from a household survey ( $N=261)$ of neighborhood residents containing both closed- and open-ended questions in English, Spanish, Vietnamese, and Chinese. Using a list of addresses for all households in the two neighborhoods (purchased from DirectMailTools, a marketing company that provides mailing information for a fee), we drew a random sample of households from four geographic quadrants in each neighborhood. We originally sent out 350 surveys to each neighborhood, then followed up with two smaller geographicallystratified random household samples (fifty additional surveys in each neighborhood) to make up for returned mail from invalid addresses. Later, we followed up with a convenience sample of surveys handed out in person at major transit stops (50 additional surveys in each neighborhood) and at ethnically-oriented organizations in both neighborhoods. In total, 888 surveys were sent to valid addresses or handed directly in person, with a response rate of $29 \%$.

In addition to the survey data, we compiled neighborhood-level summary statistics from the 1990 and 2000 decennial Census reports and the 2005-2009 American Community Survey. We also use observations from our ethnographic field notes, collected between July 2015 and February 2016, to add some depth to our interpretations. Field notes were collected by a team of six researchers (three were assigned to each neighborhood). In total, we spent approximately three days a week in each neighborhood, focusing our observations on daily life. We paid particular attention to inter-group social exchanges, sense of ownership in spaces (trash cleanup, gardens, and public art), neighboring behaviors, and the use of public spaces.

We use results from two open-ended survey questions to gather residents' perceptions of structural resources and constraints their neighborhoods. These questions 
asked, "If a friend said that they were planning to move to this neighborhood, what would you say is the best/worst thing about living here?" We coded responses and categorized them into abstract concepts, analyzing the distribution of the four most commonly raised concepts for each question. Categories for the best thing about the neighborhood include: amenities (includes codes for "restaurants," "shops," and/ or "amenities"), diversity (includes codes for "diversity"), convenience (includes codes for "walkability," "city access," "convenience," and/or "public transportation"), and community (includes codes for "neighborhood vibe," "community," and/or "family orientation"). Categories for the worst thing about the neighborhood include: safety (includes codes for "crime" and/or "safety"), nuisance (includes codes for "drugs" and/ or "homelessness"), exclusivity (includes codes for "gentrification" and/or "expensive"), and urban (includes codes for "crowded," "noise," "parking," and/or "traffic").

We use the social-psychological construct sense of community as our measure of social connectedness in the neighborhoods. Sense of community is a multidimensional scale measuring respondents' emotional orientation toward the neighborhood in terms of membership, influence, fulfillment of needs, and shared emotional connection (McMillan and Chavis, 1986). We constructed a scale from twelve survey questions, asking respondents to rate their agreement with statements such as, "I feel at home in my neighborhood," "If there is a problem in this neighborhood, people who live here get it solved," "My neighbors and I want the same thing from this neighborhood," and "People in this neighborhood generally don't get along with one another." To calculate the sense of community score, we summed the Likert scale responses with values from 1 = "Strongly Disagree" to 5 = "Strongly Agree" (reverse coding for negatively-worded questions) and then divided by twelve, so higher numbers represent greater perceptions of sense of community in the neighborhood.

We stratify descriptive analyses by race/ethnicity and homeownership. Race/ethnicity is determined from the survey question asking, "Which one group best describes the race or ethnicity that you identify with?" Respondents could choose one category from a list including, "Black/African American," "White," "Latino/Hispanic," "Asian," "Native American," and "Other." We focus these analyses on individuals from the first four groups because of extremely small sample sizes among Native American and Other groups. Homeownership is assessed from the survey question, "Do you own your home?" Responses were categorized as "Yes" and "No."

\section{Analytic Approach}

The analyses primarily rely on descriptive comparisons from survey questions and field observations. Table 1 displays neighborhood-level demographic information for both neighborhoods over the period of 1990-2010. Tables 2 and 3 collate our codes of the open-ended survey responses about the neighborhood resources and constraints according to race and homeownership. We compare proportional identification of resources and constraints across racial and socioeconomic groups to understand within-neighborhood differences, and compare overall proportional identification of resources and constraints across neighborhoods to understand between-neighborhood differences. Table 4 displays perceptions of sense of community by racial and socioeconomic groups, and stratified by neighborhood to allow for within- and betweenneighborhood comparisons. We use a one-way ANOVA procedure (proc glm in SAS) to determine perception differences among racial and socioeconomic groups within each neighborhood, and two-factor ANOVA to assess between-neighborhood differences. 
¿ Table 2. The BEST thing about this neighborhood, by Race and Homeownership

\begin{tabular}{|c|c|c|c|c|c|c|c|c|c|c|}
\hline & \multicolumn{5}{|c|}{ South End } & \multicolumn{5}{|c|}{ Fields Corner } \\
\hline & $\mathbf{N}$ & Amenities & Diversity & Convenience & Community & $\mathbf{N}$ & Amenities & Diversity & Convenience & Community \\
\hline Neighborhood & 156 & $41 \%$ & $15 \%$ & $46 \%$ & $24 \%$ & 105 & $25 \%$ & $8 \%$ & $41 \%$ & $14 \%$ \\
\hline Latino & 18 & $28 \%$ & $0 \%$ & $33 \%$ & $17 \%$ & 12 & $50 \%$ & $17 \%$ & $67 \%$ & $8 \%$ \\
\hline White & 82 & $51 \%$ & $26 \%$ & $52 \%$ & $33 \%$ & 37 & $16 \%$ & $5 \%$ & $35 \%$ & $16 \%$ \\
\hline Black & 24 & $29 \%$ & $8 \%$ & $42 \%$ & $4 \%$ & 44 & $23 \%$ & $7 \%$ & $36 \%$ & $16 \%$ \\
\hline Asian & 32 & $31 \%$ & $3 \%$ & $41 \%$ & $19 \%$ & 12 & $33 \%$ & $8 \%$ & $50 \%$ & $8 \%$ \\
\hline Renter & 81 & $35 \%$ & $7 \%$ & $38 \%$ & $17 \%$ & 77 & $27 \%$ & $6 \%$ & $40 \%$ & $13 \%$ \\
\hline Homeowner & 74 & $49 \%$ & $24 \%$ & $53 \%$ & $30 \%$ & 28 & $18 \%$ & $11 \%$ & $43 \%$ & $18 \%$ \\
\hline $\begin{array}{l}\text { Notes: } \\
\text { 1. \%s represent th } \\
\text { South End; } 28 \% \text { o } \\
\text { 2. Percentages will }\end{array}$ & $\begin{array}{l}\text { Latino } \\
\text { not sum }\end{array}$ & $\begin{array}{l}\text { ge of each subg } \\
\text { spondents in tl } \\
o \text { 100. If a resp }\end{array}$ & $\begin{array}{l}\text { up identifying } \\
\text { South End id } \\
\text { ident listed m }\end{array}$ & $\begin{array}{l}\text { his resource (e.g., } \\
\text { tified "Amenities." } \\
\text { e than one best thi }\end{array}$ & $\begin{array}{l}\% \text { of the neighbor } \\
\text {, all responses we }\end{array}$ & ood id & $\begin{array}{l}\text { tified "Amenitic } \\
\text { in the analyses }\end{array}$ & as the best & g about the neigh & rhood in the \\
\hline
\end{tabular}


Table 3. The WORST thing about this neighborhood, by Race and Homeownership

\begin{tabular}{|c|c|c|c|c|c|c|c|c|c|c|}
\hline & \multicolumn{5}{|c|}{ South End } & \multicolumn{5}{|c|}{ Fields Corner } \\
\hline Neighborhood & 156 & $13 \%$ & $19 \%$ & $23 \%$ & $27 \%$ & 105 & $45 \%$ & $10 \%$ & $4 \%$ & $18 \%$ \\
\hline White & 82 & $17 \%$ & $20 \%$ & $35 \%$ & $29 \%$ & 37 & $46 \%$ & $22 \%$ & $3 \%$ & $14 \%$ \\
\hline Black & 24 & $8 \%$ & $21 \%$ & $17 \%$ & $29 \%$ & 44 & $45 \%$ & $2 \%$ & $2 \%$ & $11 \%$ \\
\hline Asian & 32 & $13 \%$ & $13 \%$ & $6 \%$ & $25 \%$ & 12 & $42 \%$ & $8 \%$ & $17 \%$ & $33 \%$ \\
\hline Homeowner & 74 & $16 \%$ & $22 \%$ & $30 \%$ & $35 \%$ & 28 & $32 \%$ & $11 \%$ & $14 \%$ & $21 \%$ \\
\hline
\end{tabular}

Notes:

1. \% r represent the percentage of each subgroup identifying this resource (e.g., $13 \%$ of the neighborhood identified "Safety" as the worst thing about the neighborhood in the South End; $6 \%$ of Latino respondents in the South End identified "Safety.")

2. Percentages will not sum to 100 . If a respondent listed more than one worst thing, all responses were included in the analyses. 
Table 4. Sense of Community (SOC), by Race and Homeownership

\begin{tabular}{lcccc}
\hline \hline & South End & & Fields Corner & $\begin{array}{c}\text { Between-Neighborhood } \\
\text { Differences }\end{array}$ \\
\cline { 2 - 2 } & SOC & & SOC & $\begin{array}{c}\text { SOC } \\
\text { Latino }\end{array}$ \\
White & 3.4 & & 2.9 & \\
Black & 3.7 & 3.1 & \\
Asian & 3.4 & & 3.3 & \\
All Groups & $\mathrm{F}=2.4, \mathrm{p}<.10$ & $\mathrm{~F}=2.0, \mathrm{p}>.10$ & $\mathrm{~F}=6.8, \mathrm{p}<.001$ \\
White vs. Non-White & $\mathrm{F}=4.6, \mathrm{p}<.05$ & $\mathrm{~F}=1.1, \mathrm{p}>.10$ & $\mathrm{~F}=12.9, \mathrm{p}<.001$ \\
Renter & 3.5 & & 3.1 & \\
Homeowner & 3.7 & & 3.4 & \\
Homeowner vs. Renter & $\mathrm{F}=6.1, \mathrm{p}<.05$ & $\mathrm{~F}=3.7, \mathrm{p}>.05$ & $\mathrm{~F}=14.4, \mathrm{p}<.001$ \\
\hline \hline
\end{tabular}

\section{Limitations}

Though this study makes strides toward understanding social relationships and their consequences in stable, multiethnic neighborhoods, our findings should be considered in light of several limitations. First, proportions of racial/ethnic and homeownership groups in each neighborhood are not equally representative of the neighborhood demographics. Second, our relatively small sample size precludes complex multivariate analysis; instead, we primarily rely on descriptive analyses and field observations for the study's conclusions. A final limitation involves our choice of neighborhoods as the contextual unit of analysis. The use of the "neighborhood" as an ecological area has undergone considerable conceptual critique and methodological innovation in recent years (see for example, Cutchin et al., 2011). While we initially rely on administratively-defined census tracts to determine the geographic boundaries and multiethnic character of the neighborhoods we study, we are flexible and as the study proceeds explicitly incorporate residents' own perceptions and experiences into our boundary interpretations.

\section{RESULTS}

\section{Resources and Constraints}

The ability to appreciate neighborhood resources is patterned by neighborhood racial inequality (see Table 2). We see this in the South End, where Whites are overrepresented in their appreciation of three of the four most often identified neighborhood resources: "amenities" (51\% of Whites listed amenities as the best thing about the neighborhood, compared to $28 \%$ of Latinos, $29 \%$ of Blacks, and $31 \%$ of Asians), "diversity" (26\% of Whites, $0 \%$ of Latinos, $8 \%$ of Blacks, and 3\% of Asians list diversity as the best aspect), and "community" (33\% of Whites, $17 \%$ of Latinos, $4 \%$ of Blacks, and 19\% of Asians list community as the best aspect). Illustrative of Whites' greater appreciation of "community," a White resident of the South End responded, "It is a bit like Sesame Street, when you go for a quick errand on foot somewhere you are bound to find yourself in many conversations." On the other hand, another resource, "convenience," is more or less equally shared among racial groups in the South End, with the exception of Asians who are less likely to identify convenience as a resource than other groups. 
By contrast, in Fields Corner, where there is less overt racial inequality compared to the South End (Whites make up a far smaller proportion of the population and wield fewer socioeconomic resources), the best aspects of the neighborhood are shared relatively equally among racial groups. Particularly, a lower proportion of Whites identify "amenities" and "convenience" as the best thing about the neighborhood compared to other groups. Interestingly, the highest proportions of individuals recognizing these two resources is found among Latinos (50\% and 67\% respectively), and Asians are second after that (33\% and 50\% respectively). On the flip side, Whites and African Americans are more likely to identify "community" as a resource relative to both Latinos and Asians; however, the total number of affirmative responses for "community" is very small ( $n=15,14 \%$ of the neighborhood), so these may not represent real differences. Similarly, only $8 \%$ of respondents identified "diversity" as an important aspect of the neighborhood in Fields Corner (compared to $15 \%$ in the South End) and racial groups generally seem to equally share in this appreciation, with Latinos appreciating diversity the most.

Again turning to Table 2, we observe that socioeconomic inequality relates to access to resources. Homeowners constitute a minority of the population in both neighborhoods (37\% in the South End and 27\% in Fields Corner, see Table 1), however, in the South End higher proportions of homeowners identify all the best resources. In Fields Corner, on the other hand, where there is less socioeconomic inequality (most residents are lower-middle to middle class and there is very little affluence, see Table 1), homeowners and renters appear to share equally in the best resources. Instructively, one renter in Fields Corner said, "Where I live is a commuter's dream. The neighborhood is located close to schools, highways, work, hospitals and stores." Another renter in Fields Corner said, "We have everything within walking distance, such as bus stops, trains, supermarket, and parks."

We propose that this difference in access to resources across neighborhoods relates to the fact that affluent residents of the South End have more control over the types of amenities and services that are provided in the neighborhood. A walk down the commercial strip in both neighborhoods highlights these differences. In Fields Corner, the main street is lined with small ethnic cafes, hairbraiding salons, barbershops, and services such as legal assistance. In the South End, representative shops on the main commercial street include a gourmet dog bakery, high-end clothing boutiques, art and furniture stores, and real estate agencies. One resident of the South End explained, "It is quirky and artsy. It has great restaurants, Whole Foods, and a dog park." The relative lack of socioeconomic inequality in Fields Corner likely translates into more equal access to amenities that cater to the needs of all neighborhood residents, rather than the select set that can afford them.

Turning to Table 3, we make some observations about the differences between neighborhoods in terms of exposure to the worst aspects of the neighborhoods, ultimately finding that greater neighborhood disadvantage in Fields Corner is likely related to constraints experienced by all residents. The most striking comparison between neighborhoods is that $45 \%$ of respondents list "safety" as the worst aspect of the neighborhood in Fields Corner, whereas only 13\% identified "safety" in the South End. Safety concerns are evenly shared among racial and ethnic groups in Fields Corner, but renters are more likely to identify safety relative to homeowners, likely due to geographic differences in objective safety issues. In the South End, on the other hand, safety is not a major concern for any groups.

Thus, the socioeconomic inequality in the South End suggests that poor and minority residents don't have access to the best things about the neighborhood, but on the flip side they are protected from some of the dangerous, stressful aspects of 
disadvantaged neighborhoods. It could be that the larger proportion of White and affluent residents in the South End translates into more cachet in advocating for basic services to protect their quality of life. In our observations, we found the police to be a strong presence in the South End and observed instances of police interacting in pleasant, helpful ways with residents. For example, we observed one police officer saying to a homeless man, "Brother, I know it's a hot day and it's shady here, but I've told you a few times about staying away from this storefront. I hate to do this, but I've got to ask you to move."

In Fields Corner, on the other hand, we did not observe a single interaction between police and residents in the same time period. One resident of Fields Corner even responded to the question about the best thing in the neighborhood with, "There is nothing good. The best thing is to stay in your house because the community youth are killing and shooting GUNS every chance they get." Another Fields Corner resident agreed, saying the worst thing about the neighborhood is "the random gunshots every other night, so close sometimes you have to drop to the floor in the back of the house." Thus, while safety is far from the minds of most residents of the South End when identifying the "worst" aspect of the neighborhood, overall disadvantage in Fields Corner suggest that safety concerns are an ever-present reality.

The results presented in Table 3 also demonstrate the potential effects of racial inequality on identification of constraints. In the South End, which experiences more racial inequality relative to Fields Corner, Whites are more likely to identify "exclusivity," listing things such as "the rising cost of real estate," "yuppies and entitled people" moving in, and "inconsiderate Baby Boomers." In addition, Whites and Asians in the South End are more concerned about "safety" than Blacks and Latinos; given the strong geographic clustering in the South End, where most Black and Latino residents reside in areas with greater objective exposure to crime and violence, the higher concern about safety among Whites and Asians is likely due to differences in perception. "Urban" problems, such as traffic, noise, and parking, on the other hand, seem to be fairly evenly spread among racial and ethnic groups in the South End, with the exception of Latinos who were less likely to identify "urban" issues as a constraint. Looking at the identification of the worst neighborhood aspects in Fields Corner, we can see that "urban" problems are the second highest category after safety; however, unlike in the South End, Latinos and Asians in Fields Corner disproportionately identify urban problems as a concern, whereas Whites and Blacks are less concerned about "urban" problems.

Indicative of the potential relationship of socioeconomic inequality with identification of constraints, homeowners in the South End are disproportionately likely to identify all of the neighborhood problems relative to renters. On the other hand, in Fields Corner, homeowners and renters are fairly equal in their reporting of "nuisances" and "urban" problems, while "exclusivity" is a concern only among homeowners. Perhaps even more indicative of the lack of socioeconomic inequality in Fields Corner, "exclusivity" and "nuisances" are not major concerns among residents (raised by only $4 \%$ and $10 \%$ of respondents respectively.)

In sum, we make three main observations about access to resources and exposure constraints in consistently multiethnic neighborhoods. First, racial inequality appears to relate to use of neighborhood resources - evidenced by between-neighborhood racial differences. In the racially unequal South End, Whites were overrepresented relative to people of color in their appreciation of neighborhood resources; however, Whites did not have this privileged position in Fields Corner. Second, neighborhood socioeconomic inequality may also structure access to resources in multiethnic neighborhoods-evidenced by between-neighborhood differences in access to 
resources among homeowners and renters in the South End, but not in Fields Corner. Finally, neighborhood disadvantage results in greater exposure to serious constraintsevidenced by between-neighborhood differences in the identification of "safety" as the worst thing about the neighborhood in Fields Corner but not the South End.

\section{Sense of Community}

We also find within-neighborhood differences in perceptions of sense of community across racial and socioeconomic groups in both multiethnic neighborhoods (see Table 4). Descriptive statistics regarding perceptions of sense of community across groups in the South End indicate that Whites (3.7) and Blacks (3.6) score higher than Asians and Latinos (both 3.4). This racial difference is marginally significant for all groups $(F=2.4$, $p<0.10)$, and is revealed more starkly when examining the comparison of Whites versus non-Whites $(F=4.6, p<0.05)$. There are no significant differences across racial groups in Fields Corner regarding sense of community when individual groups are compared to each other $(F=2.0, p>0.10)$. Notably, Whites also do not have a privileged status relative to other groups in their perceptions of sense of community (White vs. non-White, $F=1.1, p>0.10$ ). In addition to the racial stratification in perceptions of sense of community within each neighborhood, we see socioeconomic stratification in the South End, where homeowners report significantly higher sense of community than renters (3.7 and 3.5 respectively, $F=6.1, p<0.05)$. In Fields Corner, on the other hand, there is no significant difference between homeowners and renters in perceptions of sense of community (3.4 and 3.1 respectively, $F=3.7, p>0.05$ ).

Our field observations suggest racial and socioeconomic microsegregation of public space in the South End might account for the differential perceptions of community. For example, the South End hosts a weekly Sunday open market that clearly caters to an upper class, White clientele in its sales of art, vintage clothing, and organic produce. Farther down the street is a community garden with a distinctly Chinese "feel," with a trellised archway at the entrance and all signs in both English and Chinese languages. These two public spaces provide very different opportunities for connection; the market is an open, inviting space for affluent residents to mingle and exchange news, whereas the garden has the theoretical potential to be a social space, but in reality can be a solitary space.

Beyond the different perceptions of sense of community across racial and socioeconomic groups within the neighborhoods, Table 2 also exhibits the differences between neighborhoods, with residents of all demographic groups in the South End reporting much higher levels than Fields Corner. A two-factor ANOVA reveals these racial differences to be significant across neighborhoods (all groups, $F=6.8, p<0.001$; White vs. non-White, $F=12.9, p<0.001)$. There is a similar between-neighborhood difference in perceptions of sense of community among homeowners and renters, with bomeowners in Fields Corner (3.4) perceiving lower sense of community than renters in the South End (3.5), and these between-neighborhood differences are significant $(F=14.4, \mathrm{p}<0.001)$.

Our field observations support this between-neighborhood difference in sense of community. Fields Corner does not have much public space in which to cultivate social interaction. Rather, there are a variety of organized events and private retail spaces dedicated to specific purposes. In addition, residential areas are not particularly welcoming or friendly; most homes have chain link fences with "No Trespassing" signs or stone barriers, and mailboxes are locked with keys. We did observe residents socializing with each other on their porches and sidewalks; however, as strangers walking around the neighborhood, we did not receive many friendly "hellos." Admittedly, South 
End does not feel particularly welcoming from the street either, as most people live in large apartment complexes or single-family brownstones. It is possible that social interaction is happening inside these large apartment buildings in the South End; one apartment dweller anecdotally told us his apartment is "like a dormitory," where residents joke that they should have screen doors instead of actual doors because the community is so strong.

In sum, we derive three conclusions about sense of community in consistently multiethnic neighborhoods. First, racial inequality is related to perceptions of sense of community in diverse communities. The effects of racial inequality can be seen in the within-neighborhood differences evident in the South End, where Whites perceived greater sense of community compared to other groups. Further, the betweenneighborhood comparison supports this conclusion, where the relationship of White versus non-White with sense of community was significant in the South End but not in Fields Corner. Second, socioeconomic inequality matters for community-evidenced by between-neighborhood differences, where homeownership mattered more in the socioeconomically-unequal South End. Third, we conclude that neighborhood disadvantage may override possibilities for beneficial social connections in diverse neighborhoods-evidenced by the between-neighborhood differences, where residents of the more contextually disadvantaged Fields Corner perceived lower sense of community overall compared to residents of the South End.

\section{CONCLUSION}

This study gives insight into residents' experiences in today's consistently multiethnic neighborhoods. Our in-depth, comparative case study analysis helps to adjudicate whether consistent neighborhood diversity implies true integration, or whether active intervention may be necessary to guarantee equal access to opportunities, protection from disabling constraints, and opportunities to build valuable social relationships in multiethnic neighborhoods. We find that not all residents are "hunkering down" amid increasing diversity, as Robert Putnam (2007) claims, but that Whites and homeowners have much greater access to community and its benefits in racially and socioeconomically unequal neighborhoods. Further, even amidst inequality, the presence of some affluent neighbors means that all residents may enjoy greater community and live in a safer environment compared to those in disadvantaged neighborhoods.

We find that neighborhood inequality and disadvantage configure access to resources and exposure to constraints in these consistently multiethnic neighborhoods. In the racially and socioeconomically unequal South End, Whites and homeowners have more access to the best things about the neighborhood in terms of amenities, convenience, diversity, and community, and ironically, more exposure to certain constraints as well, including exclusivity and safety. These findings support Meredith Greif's (2015) hypothesis that homeowners are more sensitive to the desirability of local characteristics, proving beneficial in advantaged communities and detrimental in disadvantaged communities. In Fields Corner where socioeconomic disadvantage is shared by all residents, the best aspects of the neighborhood are not dominated by Whites and homeowners, but all racial, ethnic, and socioeconomic groups have relatively equal access to resources. However, the relative equality in Fields Corner is not without cost; residents generally share equal access to the amenities in the neighborhood, but also share in exposure to the disadvantages, namely the high levels of crime and safety concerns. 
The racial and socioeconomic inequality in the South End also manifest in within-neighborhood differences in social relationships, with Whites and homeowners reporting greater sense of community. We also find between-neighborhood differences in the effects of neighborhood disadvantage on perceptions of sense of community. In Fields Corner, the greater neighborhood disadvantage means that all residents report lower sense of community compared to residents of the more affluent, though unequal, neighborhood of the South End. The lower sense of community in disadvantaged neighborhoods is not particularly surprising, given that residence in the neighborhood itself may be a result of constrained choice, thus residents' lack of control may influence their attachment to the community (Bailey et al., 2012).

The South End and Fields Corner represent two very different types of consistently multiethnic neighborhoods, and there are positive and negative features of both. Philip Nyden et al. (1998) brought clarity to the differences between "diverse-bydirection" and "diverse-by-circumstance" communities. Fields Corner is a prototype of a diverse-by-circumstance community in that it is less a product of organizational intervention and a more the product of social and economic forces initially beyond residents' control; there is no one group that is numerically (or politically and socially) dominant, and plentiful affordable housing and public transportation make it an attractive destination for recent immigrants with limited financial resources. The South End, on the other hand, also exhibits some of these traits but leans more toward a diverse-by-direction characterization in that resident activism during urban renewal intentionally ensured a future of racial and economic diversity, and this community has more financial resources that can be translated into political and economic influence in the neighborhood.

Overall, though social theories and domestic policies are premised on the idea that diversity is a social good, we find that neighborhood integration is not a panacea for the social problems perpetuated by residential segregation. Much to the contrary, the achievement of consistent diversity over time does not guarantee that all residents benefit from the neighborhood resources, are protected from constraints, and feel a sense of community with neighbors of different races and ethnicities. Rather, even in consistently multiethnic neighborhoods, racial and socioeconomic inequality and overall disadvantage mean that society's dominant power relations may be reproduced, whereby the White and wealthy continue to reap the greatest rewards. We suggest that neighborhood integration is still a laudable goal, but our findings imply that working toward true integration- "genuine intergroup, interpersonal doing" (King 1986, p. 118)—will require more active intervention to ensure that inequality and disadvantage do not override the potential benefits of neighborhood diversity. As bell hooks reminds us, we must maintain "vigilant awareness" of the ways inequality and disadvantage affect community building if we truly wish to interrupt the "perpetuation of domination" (2003, p. 36) as our nation diversifies.

Corresponding author: Professor Emily Walton, Department of Sociology, Dartmouth College, 6104 Silsby Hall, Hanover, NH 03755. E-mail: emily.c.walton@ dartmouth.edu

\section{REFERENCES}

Abascal, Maria, and Delia Baldassarri (2015). Love Thy Neighbor? Ethnoracial Diversity and Trust Reexamined. American Fournal of Sociology, 121(3): 722-782.

Adelman, Robert M., and Christopher Mele (2015). Race, Space, and Exclusion: Segregation and Beyond in Metropolitan America. New York: Routledge.

Alesina, Alberto, and Eliana La Ferrara (2000). Participation in Heterogeneous Communities. The Quarterly fournal of Economics, 115(3): 847-904. 
Allport, Gordon (1954). The Nature of Prejudice. New York: Addison-Wesley.

Anderson, Elijah (2011). The Cosmopolitan Canopy: Race and Civility in Everyday Life. New York: W. W. Norton \& Company.

Anderson, Elizabeth (2010). The Imperative of Integration. Princeton, NJ: Princeton University Press.

Bailey, Nick, Ade Kearns, and Mark Livingston (2012). Place Attachment in Deprived Neighbourhoods: Teh Impacts of Population Turnover and Social Mix. Housing Studies, 27(2): 208-231.

Briggs, Xavier de Souza (2005). Politics and Policy: Changing the Geography of Opportunity. In Xavier de Souza Briggs (Ed.), The Geography of Opportunity: Race and Housing Choice in Metropolitan America, pp. 310-341. Washington, DC: Brookings Institution Press.

Cattell, Vicky (2004). Having a Laugh and Mucking Together: Using Social Capital to Explore Dynamics between Structure and Agency in the Context of Declining and Regenerated Neighbourhoods. Sociology, 38(5): 945-963.

Charles, Camille Zubrinsky (2000). Neighborhood Racial Composition Preferences: Evidence from a Multiethnic Metropolis. Social Problems, 47: 379-407.

Costa, Dora L., and Matthew E. Kahn (2003). Civic Engagement and Community Heterogeneity: An Economist's Perspective. Perspectives on Politics, 1(1): 103-111.

Crowder, Kyle, Jeremy Pais, and Scott J. South (2012). Neighborhood Diversity, Metropolitan Constraints, and Household Migration. American Sociological Review, 77(3): 325-353.

Cutchin, Malcolm P., Karl Eschbach, Christine A. Mair, Hyunsu Ju, and James S. Goodwin (2011). The Socio-Spatial Neighborhood Estimation Method: An Approach to Operationalizing the Neighborhood Concept. Health \& Place, 17(5): 1113-1121.

Du Bois, W. E. B. (1899). The Philadelphia Negro. Philadelphia, PA: The University of Pennsylvania.

Du Bois, W. E. B. (2007 [1899]). The Philadelphia Negro: A Social Study, Edited by Henry Louis Gates, Jr. New York: Oxford University Press.

Ellen, Ingrid Gould (2000). Sharing America's Neigbborboods: The Prospects for Stable Racial Integration. Cambridge, MA: Harvard University Press.

Fainstein, Susan S. (2005). Cities and Diversity: Should We Want It? Can We Plan for It? Urban Affairs Review, 41(1): 3-19.

Fasenfest, David, Jason Booza, and Kurt Metzger (2004). Living Together: A New Look at Racial and Ethnic Integration in Metropolitan Neighborhoods, 1990-2000. Washington, DC: The Brookings Institution, Center on Urban and Metropolitan Policy.

Fong, Eric, and Kumiko Shibuya (2005). Multiethnic Cities in North America. Annual Review of Sociology, 31: 285-304.

Freeman, Lance (2006). There Goes the 'Hood: Views of Gentrification from the Ground Up. Philadelphia, PA: Temple University Press.

Frey, William H. (1996). Immigration, Domestic Migration, and Demographic Balkanization in America: New Evidence for the 1990s. Population and Development Review, 22(4): 741-763.

Friedman, Samantha (2008). Do Declines in Residential Segregation Mean Stable Neighborhood Racial Integration in Metropolitan America? A Research Note. Social Science Research, 37: 920-933.

Glaeser, Edward, and Jacob Vigdor (2012). The End of the Segregated Century: Racial Separation in America's Neighborhoods 1890-2010. Cambridge, MA: Center for State and Local Leadership at the Manhattan Institute.

Green, James (1975). The South End. Boston, MA: Boston 200 Neighborhood Series.

Greif, Meredith (2015). The Intersection of Homeownership, Race and Neighbourhood Context: Implications for Neighbourhood Satisfaction. Urban Studies, 52(1): 50-70.

Guest, Avery M., Charis E. Kubrin, and Jane K. Cover (2008). Heterogeneity and Harmony: Neighbouring Relationships among Whites in Ethnically Diverse Neighborhoods in Seattle. Urban Studies, 45(3): 501-526.

hooks, bell (2003). Teaching Community: A Pedagogy of Hope. New York: Routledge.

Horton, John (1995). The Politics of Diversity. Philadelphia, PA: Temple University Press.

Jacobs, Jane (2011 [1961]). The Death and Life of Great American Cities, 50th Anniversary Edition. New York: Modern Library.

Keating, W. Dennis (1994). The Suburban Racial Dilemma: Housing and Neigbborboods. Philadelphia, PA: Temple University Press.

Kennedy, Lawrence W. (1992). Planning the City Upon a Hill: Boston Since 1630. Amherst, MA: University of Massachusetts Press. 
King, Martin Luther, Jr. (1986). The Ethical Demands for Integration. In J. M. Washington (Ed.), A Testament of Hope: The Essential Writings and Speeches of Martin Luther King, Fr. pp. 117-125. San Francisco, CA: Harper \& Row.

Kleit, Rachel Garshick (2005). HOPE VI New Communities: Neighborhood Relationships in Mixed-Income Housing. Environment and Planning A, 37: 1413-1441.

Kornhauser, Ruth Rosner (1978). Social Sources of Delinquency: An Appraisal of Analytic Models. Chicago, IL: University of Chicago Press.

Krysan, Maria, Reynolds Farley, Mick P. Couper, and Tyrone A. Forman (2009). Does Race Matter in Neighborhood Preferences? Results from a Video Experiment. American fournal of Sociology, 115: 527-559.

Laurence, James (2011). The Effect of Ethnic Diversity and Community Disadvantage on Social Cohesion: A Multi-Level Analysis of Social Capital and Interethnic Relations in UK Communities. European Sociological Review, 27(1): 70-89.

Lee, Barrett A., and Lauren A. Hughes (2014). Bucking the Trend: Is Ethnoracial Diversity Declining in American Communities? Population Research and Policy Review, 34(1): 113-139.

Letki, Natalia (2008). Does Diversity Erode Social Cohesion? Social Capital and Race in British Neighbourhoods. Political Studies, 56: 99-126.

Lewis, Amanda E., John B. Diamond, and Tyrone A. Forman (2015). Conundrums of Integration: Desegregation in the Context of Racialized Hierarchy. Sociology of Race \& Ethnicity, 1(1): 22-36.

Lichter, Daniel T. (2013). Integration or Fragmentation? Racial Diversity and the American Future. Demography, 50: 359-391.

Logan, John R., and Brian J. Stults (2011). The Persistence of Segregation in the Metropolis: New Findings from the 2010 Census. Providence, RI: Russell Sage Foundation American Communities Project of Brown University.

Logan, John R., and Charles Zhang (2010). Global Neighborhoods: New Pathways to Diversity and Separation. American Fournal of Sociology, 115(4): 1069-1109.

Maly, Michael T. (2005). Beyond Segregation: Multiracial and Multietbnic Neighborboods in the United States. Philadelphia, PA: Temple University Press.

Massey, Douglas S., and Nancy A. Denton (1993). American Apartheid: Segregation and the Making of the Underclass. Cambridge, MA: Harvard University Press.

Massey, Douglas S. (2016). Residential Segregation is the Linchpin of Racial Stratification. City \& Community, 15(1): 4-7.

Mayorga-Gallo, Sarah (2014). Behind the White Picket Fence: Power and Privilege in a Multiethnic Neighborhood. Chapel Hill, NC: The University of North Carolina Press.

McMillan, David W., and David M. Chavis (1986). Sense of Community: A Definition and Theory. Fournal of Community Psychology, 25(6): 6-23.

Mennis, Jeremy, Suzanne Lashner Dayanim, and Heidi Grunwald (2013). Neighborhood Collective Efficacy and Dimensions of Diversity: A Multilevel Analysis. Environment and Planning A, 45: 2176-2193.

Miller, Elizabeth A. (2015). Cultivating and Unexpected Community: Inclusivity of Immigrant Service Workers in a Wealthy Neighborhood. Fournal of Contemporary Ethnography, 44(3): 335-361.

Neal, Zachary P., and Jennifer Watling Neal (2014). The (In)compatibility of Diversity and Sense of Community. American Fournal of Community Psychology, 53: 1-12.

Nyden, Philip, John Lukehart, Michael T. Maly, and William Peterman (1998). Neighborhood Racial and Ethnic Diversity in U.S. Cities. Cityscape: A Fournal of Policy Development and Research, 4(2): 1-17.

Pager, Devah, and Hana Shepherd (2008). The Sociology of Discrimination: Racial Discrimination in Employment, Housing, Credit, and Consumer Markets. Annual Review of Sociology, 34: 181-209.

Parisi, Domenico, Daniel T. Lichter, and Michael C. Taquino (2015). The Buffering Hypothesis: Growing Diversity and Declining Black-White Segregation in America's Cities, Suburbs, and Small Towns? Sociological Science, 2: 125-157.

Passel, Jeffrey S., and D'Vera Cohn (2008). U.S. Population Projections: 2005-2050. Washington, DC: Pew Research Center.

Pettigrew, Thomas F. (1979). Racial Change and Social Policy. Annals of the American Academy of Political and Social Science, 441: 114-131.

Portes, Alejandro, and Erik Vickstrom (2011). Diversity, Social Capital, and Cohesion. Annual Review of Sociology, 37: 461-479.

Putnam, Robert D. (2007). E Pluribus Unum: Diversity and Community in the Twenty-first Century. Scandinavian Political Studies, 30(2): 137-174. 
Reskin, Barbara (2012). The Race Discrimination System. Annual Review of Sociology, 38: 17-35. Ryan, Camille L., and Julie Siebens (2012). Educational Attainment in the United States: 2009. Washington, DC: U.S. Census Bureau.

Saltman, Juliet (1990). A Fragile Movement: The Struggle for Neigbborhood Stabilization. New York: Greenwood Press.

Sampson, Robert J., and W. Byron Groves (1989). Community Structure and Crime: Testing Social-Disorganization Theory. American fournal of Sociology, 94(4): 774-802.

Sen, Amartya (2002). Why Health Equity? Health Economics, 11: 659-666.

Squires, Gregory D., and Charis E. Kubrin (2005). Privileged Places: Race, Uneven Development, and the Geography of Opportunity in Urban America. Urban Studies, 42: 47-68.

Sturgis, Patrick, Ian Brunton-Smith, Sanna Read, and Nick Allum (2010). Does Ethnic Diversity Erode Trust? Putnam's 'Hunkering Down' Thesis Reconsidered. British Fournal of Political Science, 41(1): 57-82.

Tach, Laura M. (2014). Diversity, Inequality, and Microsegregation: Dynamics of Inclusion and Exclusion in a Racially and Economically Diverse Community. Cityscape: A Fournal of Policy Development and Research, 16(3): 13-45.

The Congress for the New Urbanism (2000). Principles for Inner City Neighborhood Design: HOPE VI and the New Urbanism. San Francisco, CA: A Collaboration of the Congress for the New Urbanism and the US Department of Housing and Urban Development.

Timberlake, Jeffrey, and John Iceland (2007). Change in Racial and Ethnic Residential Inequality in American Cities, 1970-2000. City and Community, 6: 335-365.

Tissot, Silvie (2015). Good Neighbors: Gentrifying Diversity in Boston's South End. New York: Verso.

Townley, Greg, Bret Kloos, Eric P. Green, and Margarita M. Franco (2011). Reconcilable Differences? Human Diversity, Cultural Relativity, and Sense of Community. American Fournal of Community Psychology, 47: 69-85.

Turner, Margery Austin (1998). Moving out of Poverty: Expanding Mobility and Choice through Tenant-Based Housing Assistance. Housing Policy Debate, 9(2): 373-394.

Watanabe, Paul (2009). The Rebirth of Fields Corner: Vietnamese Immigrant Entrepreneurs and the Revitalizaiton of a Boston Neighborhood. Western New England Law Review, 31: $781-795$. 